\title{
Atypical influence of the 2007 La Niña on rainfall and temperature in southeastern Australia
}

\author{
Ailie J. E. Gallant ${ }^{1}$ and David J. Karoly ${ }^{1}$ \\ Received 4 May 2009; accepted 22 June 2009; published 29 July 2009.
}

[1] Interannual climate variations associated with El Niño Southern Oscillation (ENSO) dominate rainfall and temperature variability in southeastern Australia's MurrayDarling Basin (MDB), an important region for agricultural productivity. Following a decade-long dry period, a La Niña during 2007 failed to provide above average rainfall and cool temperatures in the southern half of the MDB, typical of most La Niña events for the region. Instead, annual (winter halfyear) rainfall was $17 \%(35 \%)$ below average and maximum temperatures $0.91^{\circ} \mathrm{C}\left(1.26^{\circ} \mathrm{C}\right)$ above average. Based on the past variability between La Niña events, the combined probability of such anomalies is less than $2 \%$. It is likely that these anomalies contain some contribution from a positive Indian Ocean Dipole (IOD). However, the IOD and other large-scale circulation features are unlikely to explain the atypical conditions that occurred in the southern MDB during the 2007 La Niña. Citation: Gallant, A. J. E., and D. J. Karoly (2009), Atypical influence of the 2007 La Niña on rainfall and temperature in southeastern Australia, Geophys. Res. Lett., 36, L14707, doi:10.1029/2009GL039026.

\section{Introduction}

[2] Parts of South America, North America, Asia, Africa, Australia and New Zealand have an established relationship between rainfall and temperature variations and ENSO [Ropelewski and Halpert, 1987]. One example is in eastern Australia, where the relationship describes wetter and cooler conditions during La Niña events and drier and warmer conditions during El Niño events [Allan et al., 1996].

[3] Stochastic variability and interactions with other climatic features (that may or may not be associated with ENSO) lead to variability in rainfall and temperature between ENSO events. Such variability has been linked to the Pacific Decadal Oscillation [Mantua and Hare, 2002] and the IOD [Ashok et al., 2001]. Taking account of such interactions, rainfall and temperature variations with ENSO are well established and useful for seasonal prediction.

[4] This paper describes a La Niña event during 2007 that had atypical influences compared to the established bounds of rainfall and temperature variability in southeastern Australia's MDB. The MDB contributes 41\% of Australia's primary agricultural productivity and has experienced prolonged dry and warm conditions since the turn of the 21 st Century. Despite the development of a La Niña in mid-2007 [Hope and Watkins, 2008], rainfall deficits persisted in the southern half of the MDB (Figure 1a). Regionally averaged,

\footnotetext{
${ }^{1}$ School of Earth Sciences, University of Melbourne, Melbourne, Victoria, Australia.
}

Copyright 2009 by the American Geophysical Union. 0094-8276/09/2009GL039026
May 2007-April 2008 (June-November 2007) rainfall was $17 \%(35 \%)$ below the 1911-2007 average in the southern MDB and $10 \%(8 \%)$ above (below) average in the northern MDB. Mean maximum temperature anomalies were $-0.42^{\circ} \mathrm{C}\left(+0.28^{\circ} \mathrm{C}\right)$ in the northern and $+0.91{ }^{\circ} \mathrm{C}$ $\left(+1.26^{\circ} \mathrm{C}\right)$ in the southern MDB (Figure $\left.1 b\right)$.

[5] This paper compares the rainfall and temperature anomalies in the MDB during the 2007 La Niña to previous events to determine if such conditions are unprecedented. Other large-scale features known to influence rainfall and temperature variability in the region are also explored to determine their influence during 2007.

\section{ENSO Indices and Instrumental Data}

[6] Three indices that measure ENSO using different components of the teleconnection are used to define $\mathrm{La}$ Niña years. The SOI describes ENSO using surface pressure anomalies and is defined as the normalized pressure difference between Tahiti (representing the eastern tropical Pacific) and Darwin, Australia (representing the western tropical Pacific) [Troup, 1965]. The Niño 3.4 describes ENSO variability using sea surface temperature (SST) anomalies in the central Pacific Ocean in an area bounded by $5^{\circ} \mathrm{N}-5^{\circ} \mathrm{S}, 120^{\circ} \mathrm{W}-170^{\circ} \mathrm{W}$ [Trenberth, 1997]. The Coupled ENSO Index (CEI) combines the low frequency components of the SOI and the Niño 3.4 using the 11-month and 5-month smoothed means of the respective indices [Gergis and Fowler, 2005].

[7] All annual values are defined over a May-April year as ENSO events tend to peak in the austral summer [Nicholls, 1991; Allan et al., 1996]. A La Niña is classified when the mean annual value of an ENSO index is above (below) the 70th (30th) percentile for the CEI and SOI (Niño 3.4) (Figure 2a). This yields a similar number of $\mathrm{La}$ Niña years in all indices that correspond with documented moderate and strong La Niña events [Gergis and Fowler, 2005].

[8] The Australian Bureau of Meteorology provided rainfall and maximum temperature data from May 1911April 2008. The data are presented on a $0.05^{\circ} \times 0.05^{\circ}$ grid, which was generated through the interpolation of up to 5760 rainfall and 721 surface temperature observation stations [Jones et al., 2007]. Area-weighted regional time series of annual and winter half-year (June-November) rainfall and maximum temperature anomalies are generated for the southern MDB and the northern MDB, delineated by the $32^{\circ} \mathrm{S}$ latitude line.

[9] The annual time series are validated through a comparison with high-quality rainfall and temperature station data [Lavery et al., 1997; Della-Marta et al., 2004] using a January-December year, as this is the only period for which 

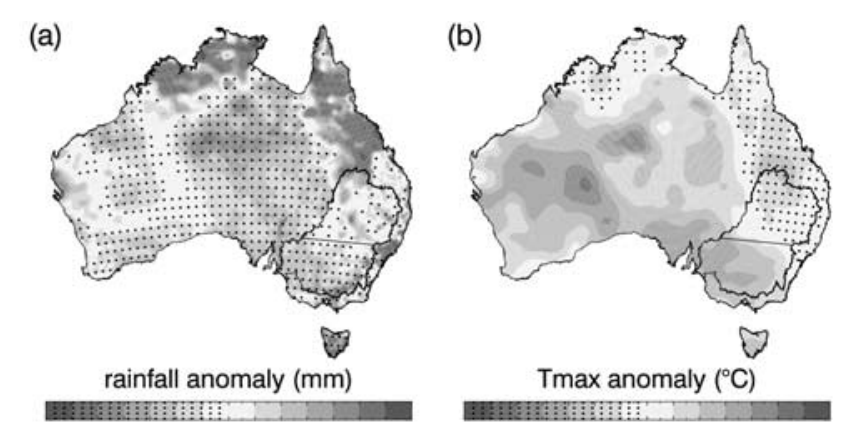

Tmax anomaly $\left({ }^{\circ} \mathrm{C}\right.$

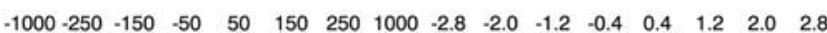

Figure 1. The May 2007-April 2008 (a) rainfall and (b) maximum temperature anomalies. The stippling indicates a negative anomaly. The Murray-Darling Basin is highlighted, with its northern and southern halves delineated at $32^{\circ} \mathrm{S}$.

high-quality data are available. The correlations between the regionally-averaged time series from the high-quality stations and the interpolated grids exceed 0.98 in all cases. The root-mean square error is less than $0.13^{\circ} \mathrm{C}$ for maximum temperature and $28 \mathrm{~mm}$ for rainfall, which equates to errors of less than 5\%. All subsequent analyses are performed using detrended data, which are calculated by removing a least-squares regression line from the time series. Detrending ensures that the anomalies are not a reflection of any long-term trends in the time series.

\section{Relationships Between Rainfall, Maximum Temperature and ENSO Events in the Murray-Darling Basin}

[10] Correlations were calculated between the annual mean SOI, CEI and Niño 3.4 indices, and annual and winter half-year rainfall and maximum temperature anomalies in

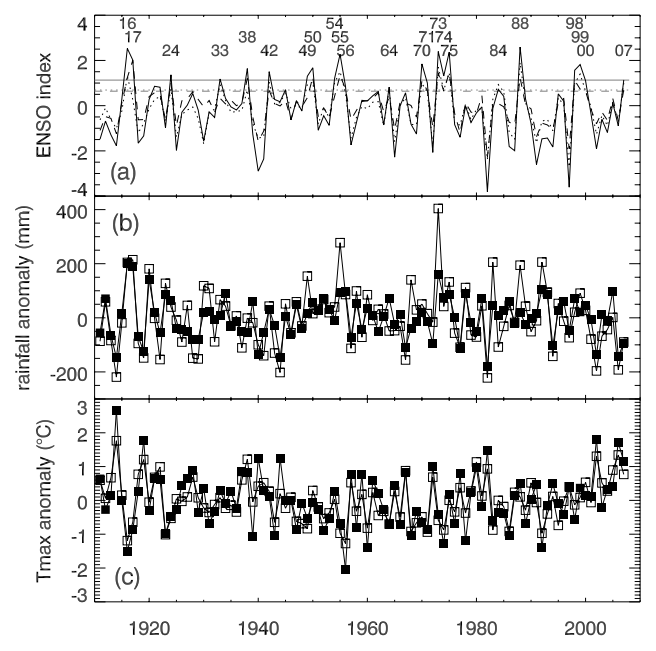

Figure 2. (a) Time series of the CEI (solid line), SOI (dashed line) and Niño 3.4 (dotted line) from 1911 to 2007. La Niña years exceed the grey lines and are annotated. For ease of comparison the SOI is divided by 10 and the Niño 3.4 index is inverted. Time series of detrended annual ( $\square$ ) and winter half-year ( $\square$ ) anomalies of southern MDB (b) rainfall and (c) maximum temperature from 1911-2007 are shown.
Table 1. Correlations Between the Detrended Time Series of Indicators of Large-Scale Climate Features and Rainfall and Maximum Temperature Anomalies in the Southern MurrayDarling Basin (SMDB) and the Northern Murray-Darling Basin (NMDB)

\begin{tabular}{lcccccc}
\hline & SOI & CEI & Niño 3.4 & MSLP & SAM & IOD \\
\hline SMDB & 0.53 & 0.48 & -0.46 & -0.37 & 0.02 & -0.39 \\
NMDB & 0.56 & 0.54 & -0.53 & -0.17 & 0.25 & -0.19 \\
& \multicolumn{7}{c}{ Maximum Temperature } \\
SMDB & -0.32 & -0.30 & 0.29 & 0.39 & 0.12 & 0.34 \\
NMDB & -0.52 & -0.50 & 0.49 & 0.29 & -0.08 & 0.29 \\
\hline
\end{tabular}

the southern and northern MDB (Table 1 shows annual correlations only). The ENSO indices explain over $21 \%$ and $28 \%$ of the variance in rainfall anomalies in the southern and northern MDB respectively (Table 1). For maximum temperature, ENSO explains over $9 \%$ and $24 \%$ of the variance in the southern and northern MDB respectively (Table 1). The stronger associations with the SOI and CEI are due to their dependence on Darwin pressure, which has a component of variability not linked with the Southern Oscillation [Trenberth, 1984]. The differences between the correlations of the annual and winter-half year rainfall and maximum temperature time series are less than 0.03 , except for maximum temperature in the northern MDB, where correlations are on the order of 0.1 stronger for the annual time series. Hence, the annual time series are representative of rainfall and maximum temperature variability associated with ENSO in both regions.

\section{The 2007 La Niña Episode in the Instrumental Record}

[11] The classification of La Niña years differs slightly for each ENSO index. However, all indices record 2007 (defined as May 2007-April 2008) as a moderate La Niña (Figure 2a). In the southern (northern) MDB, the average annual maximum temperature anomaly during a La Niña is between $-0.19^{\circ} \mathrm{C}$ and $-0.22^{\circ} \mathrm{C}\left(-0.55^{\circ} \mathrm{C}\right.$ and $\left.-0.63^{\circ} \mathrm{C}\right)$ and the average annual rainfall anomaly is between $+88 \mathrm{~mm}$ and $+106 \mathrm{~mm}(+128 \mathrm{~mm}$ and $+151 \mathrm{~mm})$, depending on the ENSO index.

[12] For the SOI and CEI indices, the 2007 La Niña in the southern MDB is the driest (detrended annual/winter halfyear rainfall anomaly of $-90 /-94 \mathrm{~mm}$ ), combined with the second warmest annual and warmest winter half-year maximum temperatures (detrended anomalies of $+0.77^{\circ} \mathrm{C}$ and $+1.15^{\circ} \mathrm{C}$ respectively) in the instrumental record (Figure $3 \mathrm{a}$ ). The 1938 La Niña (as classified by the SOI and CEI indices only) registered below average rainfall in the southern MDB (Figure $3 \mathrm{a})$, but the deficit was small $(-1.2 \mathrm{~mm})$. Winter half-year rainfall is below average $(-14 \mathrm{~mm})$ in the region during a 1971 event classified by the SOI only (Figure 3a). However, the annual rainfall anomaly is above average during this time. In the northern MDB the annual anomalies are consistent with previous La Niña events, while the winter half-year is slightly drier and warmer than an average La Niña (Figure 3b).

[13] Using the Niño 3.4 index, 2007 had the lowest (second lowest) winter half-year (annual) rainfall total during a La Niña year. The 1964 and 1984 events show 

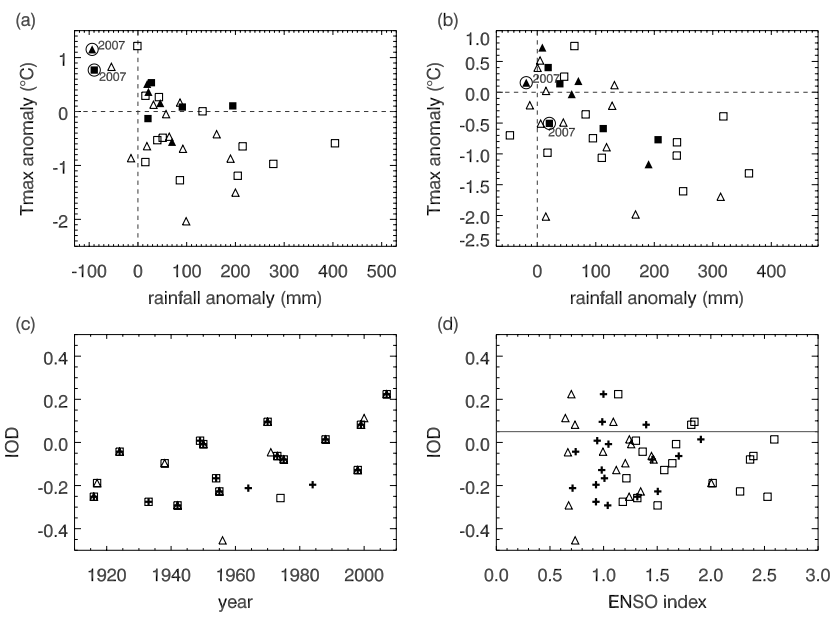

Figure 3. Annual ( $\square$ or $\square$ ) and winter half-year ( $\triangle$ or $\mathbf{\Delta}$ ) rainfall and maximum temperature anomalies during $\mathrm{La}$ Niña years (classified by the SOI) in the (a) southern Murray-Darling Basin and (b) northern Murray-Darling Basin. Open shapes show La Niña years from 1911 to 1975 and filled shapes from 1976 to 2007. The 2007 event is circled and annotated. The IOD during La Niña years only is shown (c) with time and (d) with the strength of the La Niña, defined by the SOI $(\triangle)$, CEI $(\square)$ and Niño $3.4(+)$ indices. The SOI is divided by 10 and the Niño 3.4 index is inverted.

below average annual rainfall in the southern MDB of $-49 \mathrm{~mm}$ and $-108 \mathrm{~mm}$ respectively but above average winter half-year rainfall of $+72 \mathrm{~mm}$ and $+8 \mathrm{~mm}$. However, 1964 and 1984 are not La Niña years according to the SOI and CEI. A list of ENSO events compiled by Gergis and Fowler [2005] from eight studies using instrumental and proxy records shows that only one study defines each of 1964 and 1984 as La Niña years.

[14] It is the combination of low rainfall totals and large, positive maximum temperature anomalies that makes 2007 atypical of previous La Niñas in the southern MDB (Figure 3a). The probability of such anomalies occurring is tested using a bivariate normal distribution, approximated from the sample of observed La Niña years both including and excluding 2007. The rainfall and temperature distributions satisfy tests for within-sample normality and independence. In the southern MDB, the probability that the combined 2007 rainfall and maximum temperature anomalies occurred through random variability is less than $2 \%$ for the annual data (Table 2 ) and $1.2 \%$ or less for the winter half-year data (Table 2), confirming the highly atypical conditions. In the northern MDB all probabilities are greater than $8 \%$, indicating that the conditions are more consistent with previous La Niña events.

\section{Other Influences on Rainfall and Temperature Variability in the Southern Murray-Darling Basin}

[15] Though ENSO dominates rainfall and temperature variability in eastern Australia, other large-scale features may have contributed to the atypical conditions during 2007. The regional-scale synoptic environment is examined through surface pressure (MSLP) anomalies and wind fields. Rainfall and temperature variations in south-eastern Australia also show some dependence on the Southern Annular Mode (SAM) [Hendon et al., 2007], measuring the position of the mid-latitude storm-track, and the IOD [Meyers et al., 2007], which is defined by differences in western and eastern Indian Ocean SSTs.

[16] May-April annual MSLP anomalies and mean wind fields are analysed from 1948 to 2007 using NCEP reanalysis data [Kalnay et al., 1996]. While MSLP and wind fields are not independent of ENSO (or other large-scale features), they describe the mean synoptic conditions. The association between MSLP and rainfall is stronger in the southern than the northern MDB, where the correlations are -0.37 and -0.17 respectively (Table 1$)$. The 2007 MSLP anomaly in the southern MDB is similar to several recent $\mathrm{La}$ Niñas (e.g., 1998, 1999, 2000) and there is little difference between the anomalies in the southern and northern MDB. The mean surface wind fields (not shown) and western Pacific OLR anomalies [Hope and Watkins, 2008] are further indications of a typical La Niña event.

[17] The relationships between rainfall anomalies and the SAM vary regionally (Table 1). The correlation between the detrended SAM index of Marshall [2003] and detrended southern MDB rainfall anomalies from 1957-2007 is 0.02, compared to 0.25 in the northern MDB. The SAM is near neutral when averaged from May 2007 to April 2008, with negative values during the first 6 months and positive during the latter 6 months. However, the SAM's very weak association with rainfall in the southern MDB (including during the winter half-year when the correlation is 0.12 ) means it is an unlikely contributor to the 2007 rainfall deficit.

[18] An IOD time series was generated from the HadISST data set [Rayner et al., 2003] using the methodology of Saji et al. [1999]. The correlation between the IOD and southern (northern) MDB rainfall and maximum temperature is $-0.39(-0.19)$ and $0.34(0.29)$ respectively (Table 1$)$. Ummenhofer et al. [2009] describes the dynamical relationship between the IOD and dry conditions in southeastern Australia. However, Nicholls [2009] suggests that this apparent relationship is associated only with the eastern pole of the IOD.

[19] During 2007, the IOD is positive and records its largest ever value during a La Niña (Figure 3c). The tendency towards increased IOD values during La Niña years since the 1960s (Figure 3c) reflects a positive trend in the annual IOD time series that is not related to ENSO. The

Table 2. Probabilities that the 2007 Annual and Winter Half-Year Maximum Temperature and Rainfall Anomalies in the Southern Murray-Darling Basin (SMDB) and the Northern Murray-Darling Basin (NMDB) Occurred Through Random Variability ${ }^{\mathrm{a}}$

\begin{tabular}{|c|c|c|c|}
\hline & $\begin{array}{c}\text { SOI } \\
(n=17)\end{array}$ & $\begin{array}{c}\text { CEI } \\
(n=18) \\
\end{array}$ & $\begin{array}{l}\text { Niño } 3.4 \\
(n=17)\end{array}$ \\
\hline \multicolumn{4}{|c|}{ Annual } \\
\hline SMDB & $2.0 \%(1.0 \%)$ & $1.8 \%(0.9 \%)$ & $1.2 \%(0.4 \%)$ \\
\hline NMDB & $14 \%(13 \%)$ & $9 \%(8 \%)$ & $17 \%(16 \%)$ \\
\hline \multicolumn{4}{|c|}{ Winter Half-Year } \\
\hline SMDB & $1.0 \%(0.3 \%)$ & $1.2 \%(0.4 \%)$ & $0.6 \%(0.1 \%)$ \\
\hline NMDB & $9.2 \%(8.2 \%)$ & $8.2 \%(7.0 \%)$ & $8.2 \%(6.9 \%)$ \\
\hline
\end{tabular}

${ }^{\mathrm{a}}$ All probabilities were generated from a bivariate normal distribution estimated from $n$ sample observations during La Niña events from 19112007, and $n-1$ samples excluding the 2007 event (in parentheses). 
combination of a La Niña and a positive IOD is uncommon, with just five examples in the instrumental record (1970, 1988, 1999, 2000 and 2007). Meyers et al. [2007] shows a preference for positive IOD events to coincide with El Niño events, which may be due to some dependence of the phenomena on ENSO [Allan et al., 2001]. Previous cases of positive IODs and La Niñas of similar strengths to 2007 occurred in 1970, 1999 and 2000 (Figure 3d). While these years experienced a range of annual (winter half-year) maximum temperature anomalies of between $-0.64^{\circ} \mathrm{C}$ and $+0.53^{\circ} \mathrm{C}$, the annual and winter half-year rainfall totals were at least $6 \%$ above average in the southern MDB.

[20] The positive IOD cannot be excluded as a contributor to the atypical conditions in the southern MDB during 2007, as rainfall and temperature can be sensitive to small changes in Indian Ocean SSTs [Meyers et al., 2007]. However, in comparison with previous combinations of positive IODs and La Niña events the magnitudes of the anomalies are still unusual, though this cannot be robustly tested due to the small sample of years experiencing such a combination.

\section{Conclusion}

[21] Southeast Australia's MDB has an established relationship between rainfall and temperature and ENSO that is useful for seasonal prediction. Since 1911, most La Niña events have been associated with annual and winter halfyear rainfall that is above average and near or below average maximum temperatures. However, during a moderate La Niña in 2007, the southern half of the MDB experienced a combination of below average rainfall and above average maximum temperatures that was significant at the $2 \%$ level or less, indicating that the variations of rainfall and temperature with ENSO may be changing in this region.

[22] Nicholls et al. [1996] describe a shift towards warmer and wetter conditions for a given value of the SOI from the 1970s to the mid-1990s using data averaged over Australia. In this study, additional data and assessment on a smaller regional scale have lead to differing results, showing the importance of considering regional variations. The southern MDB is one example of a region where the typical patterns of climate variability associated with ENSO have been challenged. Changes in variations of rainfall and temperature associated with ENSO would have consequences for seasonal prediction.

[23] The reasons for the atypical conditions in the southern MDB and the disparity of the conditions between the two regions are unclear. Using detrended data has shown that the 2007 anomalies are not a reflection of long-term trends. There may have been some influence from a positive IOD. However, previous combinations of positive IOD and La Niña events have always yielded above average annual and winter half-year rainfall in the southern MDB. Other large-scale features traditionally contributing to rainfall and temperature variability in the southern MDB cannot explain the anomalies experienced during 2007. Nor can they explain the disparity in the anomalies between the southern and northern MDB.

[24] Acknowledgments. This research was supported by the Australian Research Council through the Discovery Projects funding scheme (project FF0668679).

\section{References}

Allan, R. J., J. Lindsay, and D. Parker (1996), El Niño Southern Oscillation and Climate Variability, 405 pp., CSIRO, Melbourne, Victoria, Australia. Allan, R. J., D. Chambers, W. Drosdowsky, H. Hendon, M. Latif, N. Nicholls, I. Smith, R. Stone, and Y. Tourre (2001), Is there an Indian Ocean dipole, and is it independent of the El Niño Southern Oscillation?, CLIVAR Exchanges, 6, 18-21.

Ashok, K., Z. Guan, and T. Yamagata (2001), Impact of the Indian Ocean dipole on the relationship between the Indian monsoon rainfall and ENSO, Geophys. Res. Lett., 28, 4499-4502, doi:10.1029/ 2001GL013294.

Della-Marta, P., D. Collins, and K. Braganza (2004), Updating Australia's high-quality annual temperature dataset, Aust. Meteorol. Mag., 53, $75-93$.

Gergis, J. L., and A. M. Fowler (2005), Classification of synchronous oceanic and atmospheric El Niño-Southern Oscillation (ENSO) events for paleoclimate reconstruction, Int. J. Climatol., 25, 1541-1565, doi:10.1002/joc. 1202 .

Hendon, H. H., D. W. J. Thompson, and M. C. Wheeler (2007), Australian rainfall and surface temperature variations associated with the Southern Hemisphere Annular Mode, J. Clim., 20, 2452-2467, doi:10.1175/ JCLI4134.1.

Hope, P., and A. B. Watkins (2008), Seasonal climate summary southern hemisphere (spring 2007): La Niña finally takes hold, Aust. Meteorol. Mag., 57, 255-268.

Jones, D. A., W. Wang, and R. Fawcett (2007), Climate data for the Australian Water Availability Project, final milestone report, 37 pp., Aust. Bur. of Meteorol., Melbourne, Victoria, Australia.

Kalnay, E., et al. (1996), The NCEP/NCAR 40-year reanalysis project, Bull. Am. Meteorol. Soc., 77, 437-471, doi:10.1175/1520-0477(1996) 077<0437:TNYRP $>2.0 . \mathrm{CO} ; 2$

Lavery, B., G. Joung, and N. Nicholls (1997), An extended high-quality historical rainfall data set for Australia, Aust. Meteorol. Mag., 46, 27-38.

Mantua, N. J., and S. R. Hare (2002), The Pacific Decadal Oscillation, J. Oceanogr., 58, 35-44, doi:10.1023/A:1015820616384.

Marshall, G. J. (2003), Trends in the Southern Annular Mode from observations and reanalyses, J. Clim., 16, 4134-4143, doi:10.1175/15200442(2003)016<4134:TITSAM >2.0.CO;2.

Meyers, G., P. McIntosh, L. Pigot, and M. Pook (2007), The years of El Niño, La Niña, and interactions with the tropical Indian Ocean, J. Clim., 20, 2872-2880, doi:10.1175/JCLI4152.1.

Nicholls, N. (1991), The El Niño-Southern Oscillation and Australian vegetation, Plant Ecol., 91, 23-36, doi:10.1007/BF00036045.

Nicholls, N. (2009), Local and remote causes of the southern Australian autumn-winter rainfall decline, 1958-2007, Clim. Dyn., doi:10.1007/ s00382-009-0527-6.

Nicholls, N., B. Lavery, C. S. Frederiksen, and W. Drosdowsky (1996), Recent apparent changes in the relationships between El Niño-Southern Oscillation and Australian rainfall and temperature, Geophys. Res. Lett., 23, 3357-3360, doi:10.1029/96GL03166.

Rayner, N. A., D. E. Parker, E. B. Horton, C. K. Folland, L. V. Alexander, D. P. Rowell, E. C. Kent, and A. Kaplan (2003), Global analyses of seas surface temperature, sea ice, and night marine air temperature since the late nineteenth century, J. Geophys. Res., 108(D14), 4407, doi:10.1029/ 2002JD002670.

Ropelewski, C. F., and M. S. Halpert (1987), Global and regional scale precipitation patterns associated with the El Niño-Southern Oscillation, Mon. Weather Rev., 115, 1606-1626, doi:10.1175/1520-0493(1987) 115<1606:GARSPP $>2.0 . \mathrm{CO} ; 2$.

Saji, N. H., B. N. Goswami, P. N. Vinayachandran, and T. Yamagata (1999), A dipole mode in the tropical Indian Ocean, Nature, 401, $360-363$

Trenberth, K. (1984), Signal versus noise in the Southern Oscillation, Mon. Weather Rev., 112, 326-332, doi:10.1175/1520-0493(1984)112<0326: SVNITS $>2.0 . \mathrm{CO} ; 2$

Trenberth, K. (1997), The definition of El Niño, Bull. Am. Meteorol. Soc., 78, 2771-2777, doi:10.1175/1520-0477(1997)078<2771:TDOE$\mathrm{NO}>2.0 . \mathrm{CO} ; 2$.

Troup, A. (1965), The Southern Oscillation, Q. J. R. Meteorol. Soc., 91, 490-506, doi:10.1002/qj.49709139009.

Ummenhofer, C. C., M. H. England, P. C. McIntosh, G. A. Meyers, M. J. Pook, J. S. Risbey, A. Sen Gupta, and A. S. Taschetto (2009), What causes southeast Australia's worst droughts?, Geophys. Res. Lett., 36, L04706, doi:10.1029/2008GL036801.

A. J. E. Gallant and D. J. Karoly, School of Earth Sciences, University of Melbourne, Melbourne, Vic 3010, Australia. (agallant@unimelb.edu.au) 


\section{University Library}

\section{- M M N E R VA A gateway to Melbourne's research publications}

Minerva Access is the Institutional Repository of The University of Melbourne

Author/s:

Gallant, Ailie J. E.;Karoly, David J.

Title:

Atypical influence of the 2007 La Nina on rainfall and temperature in southeastern Australia

Date:

2009

Citation:

Gallant, A. J. E., \& Karoly, D. J. (2009). Atypical influence of the 2007 La Nina on

rainfall and temperature in southeastern Australia. Geophysical Research Letters, 36, doi:10.1029/2009GL039026.

Publication Status:

Published

Persistent Link:

http://hdl.handle.net/11343/32774 